\title{
EDITORIAL
}

\section{Estimated costs of neurotic disorder in UK general practice $1985^{1}$}

Given finite resources, we cannot afford all the health care that it is possible to provide. The community has to make a choice, and the objective of the choice is to get the most effective treatment, for the least cost, to provide the greatest possible decrease in suffering. Resources, both in terms of treatment and of research programmes, need to be targetted towards those illnesses which cause the most suffering to the whole community.

The social and political implications of economic assessments of illness are well exemplified in the recent National Audit Office (1989) Report by the Comptroller and Auditor General National Health Service: Coronary Heart Disease. The cost of treating heart disease - estimated at over $£ 500$ million per year - was used to justify the need for a coordinated Government response. However, no mention is made in the Report of the costs of treatment for other illnesses.

Prevalence statistics and mortality rates provide crude measures of the importance of different diseases. This editorial aims to present a more comprehensive estimate of the burden due to one group of illnesses, the neurotic disorders (Table 1). Expressing all elements of this burden in economic terms provides a detailed measure of the significance of neurotic disorder in the community, and a structure for comparing the cost of neurosis with that of other illnesses and with other activities in the community.

In order to provide a context for the analysis, we decided to compare the cost of neurotic disorder with that of a physical disorder treated chiefly in general practice - uncomplicated hypertension an illness of similar prevalence but little clinical overlap.

Table 1. Neuroses classified according to ICD-9*

\begin{tabular}{|c|c|c|c|}
\hline Diagnosıs & ICD number & Diagnosis & ICD number \\
\hline $\begin{array}{l}\text { Anxiety } \\
\text { Hysteria } \\
\text { Phobic states } \\
\text { Obsessive compulsive disorders } \\
\text { Neurotic depression }\end{array}$ & $\begin{array}{l}(\text { ICD 300) } \\
(\text { ICD 300.1) } \\
(\text { ICD 300.2) } \\
\text { (ICD 300.3) } \\
(\text { ICD 300.4, 311) }\end{array}$ & $\begin{array}{l}\text { Neurasthenia } \\
\text { Other neuroses } \\
\text { Hypochondriasis } \\
\text { Physiological malfunction arising from } \\
\text { mental factors }\end{array}$ & $\begin{array}{l}\text { (ICD 300.5) } \\
(\text { ICD 300.6, 300.8, 300.9) } \\
(\text { ICD 300.7) } \\
(\text { ICD 306) }\end{array}$ \\
\hline
\end{tabular}

- MSGP-3 uses the ICD-9 classification; previous studies use ICD-8, under which results for hypochondriasis and physiological malfunction of mental origin are aggregated.

\section{BACKGROUND}

\section{Neurosis}

'Neurosis' denotes a group of psychiatric disorders usually regarded as psychogenic and manifesting themselves in the form of certain groups of psychological, social and physical symptoms. As Fischer-Homberger (1983) points out, the term 'like any of our conceptual tools, has several historical roots, for neither the idea of psychogenesis nor its various symptoms were always associated with it'.

For the present purpose, a generally accepted concept of neurosis such as that outlined in the ninth revision of the International Classification of Diseases (WHO, 1978) suffices: the principal

' Address for correspondence: Dr G. Wilkinson, General Practice Research Unit, Institute of Psychiatry, De Crespigny Park, London SE5 8AF. 
argument proposed there is that though the distinction between neurosis and psychosis is difficult and contentious, the nomenclature should be retained in view of its wide use.

It is apparent that the vast majority of diagnosed neurotic disorder presents and is managed in primary care settings. Shepherd et al. (1966) found that over three-fifths of psychiatric patients identified in their general practice survey were adjudged to be suffering from neurosis. At the same time, only a tiny minority of identified cases of psychiatric disorder - about 1:20-were noted to have been under specialist care at any time during the survey year.

\section{Uncomplicated hypertension (ICD No. 401.1, 401.9, 405 PT)}

Hypertension is a common, sometimes chronic physical condition usually treated entirely in general practice. There is no natural break between normality and abnormality in blood pressure, so the definition is empirical. The consulting rate of hypertension in general practice is similar to that of neurosis i.e. 130 consultations per 1000 at risk (Royal College of General Practitioners, Office of Population, Census and Surveys \& Department of Health and Social Security (MSGP3), 1986). Like neurosis, about twice as many women as men are affected, the symptoms are usually minor, the prognosis is generally favourable, and many patients do not require drug treatment (Fry, 1980). However, one of the most important differences between hypertension and neurosis is the difference in the age structure of the patients affected - the peak consulting rates being in the age-groups 45-64 and 65-74 respectively (MSGP3, 1986).

The evidence concerning the prevalence of psychiatric symptoms in hypertensives is conflicting, but it is noteworthy that in a study conducted in association with the MRC hypertension trial in general practice, there was no increase in psychiatric morbidity after diagnosis of hypertension or during one year on the trial (Mann, 1984). Mann (1984) also found that there was no correlation between a measure of emotional distress and blood pressure level.

\section{Economic analysis}

The point of departure for economic analysis is the concept of opportunity cost : what could we have had, had we chosen to do something other than what we did do? Consequently, economic analyses of health care have tended to concentrate on obvious choices; comparing treatment with no treatment, or one treatment programme with another.

Black \& Pole (1975) recommended that the importance of an illness be estimated by constructing a quantitative assessment of the relative burden on the health service and on the health of the nation. Their study compared the burden caused by 54 categories of disease, in terms of in-patient days, out-patient referrals, GP consultations, sickness absence and mortality. Within each index used, there emerged an implied objective worth pursuing; but there was no criterion for ranking these objectives across indices, without a common unit of account.

Since then there have been several analyses of the economic effects of individual illnesses or groups of illnesses (Berry \& Boland 1977; Birnbaum 1978; Weisbrod 1979, Hartunian, 1980). Cooper \& Rice (1976) provide a methodology for costing illness, based on its prevalence. The total cost is considered to be the value to society of all resources consumed as a result of the diagnosis, treatment and repercussions of the particular disorder during the period in question.

In the field of mental health, there have been numerous economic comparisons of treatment by specialist mental health professionals with the care given by GPs or other types of specialists (Gunderson \& Mosher, 1975; Weisbrod et al. 1980; Fenton et al. 1982; McKechnie et al. 1982; Mangen et al. 1983; Ginsberg et al. 1984; Balestrieri et al. 1988). Each presents a distinct choice which is of relevance to health service policy-makers. When considering categories of illness, the choice is less clear. If we lose more from neuroses than from hypertension, we cannot choose to exchange patients with neuroses for those suffering from hypertension. But we can choose to target treatment and research efforts on the more economically significant condition.

There have been fewer assessments of the economic burden of mental disorder. One study compared the cost of schizophrenia with that of a major physical disorder, acute myocardial 
infarction (Andrews et al. 1985). Its conclusion that schizophrenia accounted for half as great an economic loss as that caused by heart attacks contrasts with the distribution of research funds between the two illnesses. Also significant was the finding that the indirect cost of lost production accounts for more than half of the economic cost of schizophrenia.

Government estimates of the costs of minor psychiatric morbidity in the secondary care setting are enormous : $£ 189,712,000$ and $£ 30,731,000$ at 1985 prices, respectively, for hospital in-patient and out-patient expenditure (Department of Health Memo, September 14 1988). However, there has been no economic analysis of the costs of neurosis treated in general practice, despite the fact that $18 \%$ of National Health Service (NHS) costs in 1987 were incurred there (Office of Health Economics, 1987).

\section{THE STUDY}

Neurosis imposes costs on individuals and the community, directly and because of lost opportunities. Following the methodology used by Herzman (1983), our study is based on the question: Had we been able to eliminate all neurotic disorder in 1985-6, how much lower would the costs of care have been, and how much more production could have been expected, ceteris paribus?

In order to provide a context for the analysis, we decided to compare the cost of neurotic disorder with that of a comparable physical disorder treated chiefly in general practice - hypertension.

We restrict the analysis to patients treated entirely in general practice, and to two sources for the costs of disorder: (a) direct costs of treatment and care; and (b) indirect costs of lost productivity.

\section{Calculation of direct costs}

The direct costs of illness fall into three groups: (i) consultation, referral and drugs - falling on the NHS; (ii) personal and travel - falling on individuals; (iii) personal social services - falling on Central and Local Government.

\section{Costs of consultation and drugs}

Consultation. Calculation of the costs of providing GP care for neurosis and hypertension are based on figures from Morbidity Statistics from General Practice (Royal College of General Practitioners, $1979,1986)$. This large survey recorded all consultations and home visits for 48 practices and 332270 patients in the year 1981-2. By comparing the survey with its two predecessors, trends in morbidity were estimated, enabling us to extrapolate to 1985 .

The survey gives data for the number of surgery consultations, home visits and referrals per 1000 persons registered with a GP in the sample. Scaling up these figures by the population of the UK in 1985 gives the total number of consultations, home visits and referrals for which a diagnosis of the relevant disorder was made.

The cost of providing these services was calculated from information on the average length of a GP consultation, and on the total costs of general medical services in general practice (Health and Personal Social Services Statistics for 1985-DHSS (1987)). Consultations where a diagnosis of neurotic disorder is made tend to be longer than most. In our calculations we assumed an average consultation time of 14 minutes, with 6 minutes for physical diagnoses (Westcott, 1977), and 15 minutes for a home visit, as is customary. From the time spent on each sort of consultation, the cost per hour of GP time was calculated.

Referrals to secondary care. Face-to face consultations are only part of the service provided by GPs. A considerable portion of GPs' time is taken up by referring patients to secondary care. Fry (personal communication, 1988) estimates that the average cost, in terms of time and expenses, of

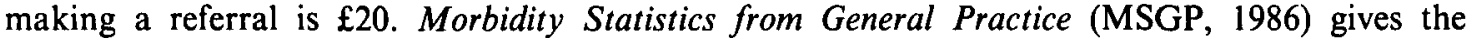
proportion of consultations for neurosis which result in a referral as approximately $1.8 \%$.

Hypertension is even more likely to be treated exclusively by the GP; in only $0.6 \%$ of consultations was a referral made. 
Psychotropic drugs prescribed for neurotic disorders (see Appendix A). The costs of the psychotropic drugs commonly used in the treatment of neurotic disorder were obtained from the Department of Health statistics division (personal communication, 1988). However, psychotropic drug costs cannot be calculated solely according to the total cost of the relevant drugs. As much as $17 \%$ of prescriptions for such drugs are dispensed for non-psychiatric complaints such as cardiovascular disease (Williams, 1978). Since statistics for prescription numbers are not divided by diagnosis, DHSS figures for prescriptions were adjusted accordingly.

Drugs prescribed for hypertension. The costs of the three groups of drugs ('drugs acting on the heart', diuretics and anti-hypertensive drugs) which are used in the treatment of hypertension were obtained from the Department of Health, as above. From the relative frequency of consultation of the conditions for which 'drugs acting on the heart' and diuretics are prescribed in general practice, we assumed that $50 \%$ were used to treat hypertension. Similarly, we assumed that $50 \%$ of antihypertensive drugs were used to treat uncomplicated hypertension.

\section{Personal costs}

People who are ill suffer direct costs because of their illness. The major cost of treatment to patients is from prescription charges. In $1985,19 \%$ of prescriptions were eligible for charge, at $£ 2.00$ per prescription. We assumed that this proportion was the same for all the drugs relevant to this study.

Although it can be expensive to travel to see a doctor, such costs are negligible for treatment in general practice since most people live close to a surgery.

\section{Social services}

Nearly $£ 3$ billion were spent on personal social services in 1985 . This figure is broken down into the various services provided, but not disaggregated according to the reason for the service provided. So although it is a reasonable assumption that a proportion of personal social services were necessitated by the presence of neurotic disorder or hypertension, we decided not to attempt to quantify this cost in our analysis.

\section{Calculation of indirect costs}

In addition to spending money directly on the consequences of neurosis and hypertension, the community bears further substantial costs. One of the most important ingredients of the total cost of these conditions is the indirect cost of lost production. Lost production falls into three categories: primary productive losses - work lost to people in 1985 because they are too ill to work; discounted future earnings of those whose illness caused them to retire or die prematurely; and, secondary productive losses, the result of people leaving the workforce to care for an ill person or suffering a reduction in their productivity because a co-worker is unwell.

\section{Primary losses}

The simplest way to measure the value of this loss is to calculate the amount of wages paid to people missing work because of illness. The market for labour is assumed to operate smoothly, so that each employee is paid exactly the monetary value of what he or she produces. This is the approach taken in most calculations of indirect costs (Herzman, 1983; Ginsberg \& Marks, 1977). But as well as assuming a perfect labour market, the calculation assumes that the figures for missed work accurately reflect the number of days of productive work lost: there are a number of reasons why they do not.

First, the official figures ignore the production of those who work in the home. There were 4.9 million housewives in the UK in 1985 (Social Trends, 1987), and we assumed that their sickness absence was the same as for employed women. Secondly, DHSS statistics record only spells of absence for which sickness benefit can be claimed, and disaggregate cause only by broad ICD categories. So the number of days of certified incapacity due to mental disorder given in the 1985 Social Security Statistics (DHSS, 1987) cover only employees who have already taken eight weeks 
leave in the current year, and also include those people with chronic, serious mental disorder, who have been absent from work for over a year.

The effect of screening out employees' first eight weeks of absence is perceptible by looking at the change in the number of spells which occurred when the system was introduced in 1983. A slowly declining trend of 136000 spells for mental disorder in 1982/3 was succeeded by a sharp drop to 57000 spells in $1983 / 4$. The decline was even more dramatic for influenza; a uniformly short-term illness. Spells dropped from 523000 to 24000 , thereafter remaining fairly steady. So it seems plausible to suggest that the drop of 79000 spells for mental disorder is overwhelmingly attributable to short-term illness. We extrapolated the trend which existed before 1983, but excluded those spells which did qualify for benefit in 1985, to give the number of spells of certificable short-term sick leave attributable to neurotic disorder in 1985. The average length of a spell - 12 working days - was calculated from the 1979-80 figures, the last to include spells of up to three days (DHSS, 1979, 1980, 1981, 1982).

The wages of employed men and women in 1985 were taken from data in Social Trends (Central Statistical Office, 1987) (see Table 2). The economic value of housewives' work was taken to be the average female wage.

\section{Discounted future earnings}

It is well documented that neurosis treated in psychiatric hospital is associated with increased mortality (Sims, 1978; Sims \& Prior, 1978). However, there is little evidence that this phenomenon extends to neurosis managed in general practice. Sims (1978) observed that the risk of mortality increased with the severity of neurotic disorder. Therefore, we assumed that the presence of neurotic disorder did not imply an increased likelihood of premature mortality.

Similarly, because of the concentration of hypertension among older people, (over $65 \%$ of episodes occured to people over 65 in the 1981-2 survey) we assumed that the number of people who died prematurely - before normal retirement age - was negligible.

Secondary losses

These are important repercussions of any disorder, however, they are difficult to quantify, and marginal to the cost of the disorders considered here.

Table 2. Unit costs of consultation, referral and sickness absence

\begin{tabular}{|c|c|c|c|}
\hline & fp. & & $\varepsilon_{\text {p. }}$ \\
\hline $\begin{array}{l}\text { General practice consultations } \\
\text { physical diagnosis ( } 6 \text { minutes) }\end{array}$ & 4.48 & $\begin{array}{l}\text { Prescription charge } \\
\text { Day's sickness leave }\end{array}$ & 2.00 \\
\hline psychoneurotic diagnosis (14 minutes) & 10.46 & men & 38.48 \\
\hline home visit (15 minutes) & 11.21 & women & 25.28 \\
\hline Referral from general practitioner & 20.00 & & \\
\hline
\end{tabular}

\section{FINDINGS}

The unit costs of consultation, referral and sickness absence are shown in Table 2 . Tables $3 \& 4$ show the numbers of general practice consultations and home visits.

The total direct and indirect cost of neurotic disorder in UK general practice for 1985 is estimated at $£ 373$ million (Tables $5 \mathrm{a} / \mathrm{b} \& 6 \mathrm{a} / \mathrm{b}$ ). This is equivalent to just over $9 \%$ of the total spent on the family practitioner services in 1984-5. The total cost of uncomplicated hypertension was $£ 337$ million. As can be seen from Tables 5 and 6, the majority of the cost of neurotic disorder is due to lost production rather than direct costs of care. The size of the commitment we are making to this illness, and the distribution of costs between treatment and lost production, has important implications for future health policy, as is discussed below. While uncomplicated hypertension costs about the same as neurotic disorder, there are marked differences when the costs are disaggregated. 
Table 3. Consultations in general practice

\begin{tabular}{|c|c|c|c|c|c|c|}
\hline \multirow[b]{2}{*}{ Disorder } & \multirow{2}{*}{$\begin{array}{l}\text { ICD } \\
\text { code }\end{array}$} & & \multicolumn{3}{|c|}{ Consultations per 1000 at risk } & \multirow{2}{*}{$\begin{array}{c}\text { Total consultations } \\
1985\end{array}$} \\
\hline & & & 1972 & $1982^{*}$ & $1985^{*}$ & \\
\hline Anxiety disorder & 300 & $\begin{array}{c}\mathbf{M} \\
\mathbf{F}\end{array}$ & $\begin{array}{r}49 \cdot 6 \\
106 \cdot 9\end{array}$ & $\begin{array}{l}33 \cdot 0 \\
77 \cdot 0\end{array}$ & $\begin{array}{l}26 \cdot 4 \\
65 \cdot 0\end{array}$ & $\begin{array}{r}728640 \\
1484795\end{array}$ \\
\hline Depressive disorder & 300.4 & $\begin{array}{c}\mathbf{M} \\
\mathbf{F}\end{array}$ & $\begin{array}{r}55 \cdot 7 \\
155 \cdot 3\end{array}$ & $\begin{array}{r}35 \cdot 2 \\
105 \cdot 7\end{array}$ & $\begin{array}{l}27.0 \\
91 \cdot 5\end{array}$ & $\begin{array}{r}745200 \\
2090135\end{array}$ \\
\hline All other neuroses & $300.1-300.9$ & $\begin{array}{c}\mathbf{M} \\
\mathbf{F}\end{array}$ & $\begin{array}{l}22 \cdot 9 \\
39 \cdot 4\end{array}$ & $\begin{array}{l}12 \cdot 7 \\
27 \cdot 0\end{array}$ & $\begin{array}{c}8.6 \\
22.04\end{array}$ & $\begin{array}{l}237360 \\
503460\end{array}$ \\
\hline All neuroses & & $\begin{array}{c}\mathrm{M} \\
\mathrm{F}\end{array}$ & $\overline{-}$ & - & $\begin{array}{r}62 \cdot 0 \\
178 \cdot 5\end{array}$ & $\begin{array}{l}1711200 \\
4078390\end{array}$ \\
\hline Hypertension & & $\begin{array}{c}\mathbf{M} \\
\mathbf{F}\end{array}$ & $\begin{array}{r}73 \cdot 1 \\
109 \cdot 8\end{array}$ & $\begin{array}{l}113 \cdot 3 \\
155 \cdot 1\end{array}$ & $\begin{array}{l}129 \cdot 4 \\
173 \cdot 2\end{array}$ & $\begin{array}{l}3570900 \\
5023400\end{array}$ \\
\hline All diseases & & $\begin{array}{l}\mathbf{M} \\
\mathbf{F}\end{array}$ & $\begin{array}{l}2673 \cdot 3 \\
3601 \cdot 4\end{array}$ & $\begin{array}{l}2710 \cdot 5 \\
4021 \cdot 4\end{array}$ & $\begin{array}{l}2725 \cdot 4 \\
4189 \cdot 4\end{array}$ & $\begin{array}{r}75221040 \\
121492600\end{array}$ \\
\hline
\end{tabular}

- The RCGP supplementary classification for social, marital and family problems was introduced between the 1972 and 1982 surveys. This partially accounts for the reduction in diagnoses of neurosis during this period. However, there is a genune downward trend. The projected 1985 figure assumes that this trend persisted between 1982 and 1985.

Table 4. Home visits and surgery consultations

\begin{tabular}{|c|c|c|c|c|c|c|c|c|c|}
\hline \multirow[b]{2}{*}{ Disorder } & \multirow[b]{2}{*}{$\begin{array}{l}\text { ICD } \\
\text { code }\end{array}$} & & \multicolumn{2}{|c|}{ Total number of } & \multirow[b]{2}{*}{ Disorder } & \multirow[b]{2}{*}{$\begin{array}{l}\text { ICD } \\
\text { code }\end{array}$} & & \multicolumn{2}{|c|}{ Total number of } \\
\hline & & & $\begin{array}{l}\text { Home } \\
\text { visits }\end{array}$ & $\begin{array}{c}\text { Surgery } \\
\text { consultations }\end{array}$ & & & & $\begin{array}{l}\text { Home } \\
\text { visits }\end{array}$ & $\begin{array}{c}\text { Súrgery } \\
\text { consultations }\end{array}$ \\
\hline Anxiety disorder & 300 & $\begin{array}{l}\mathbf{M} \\
\mathbf{F}\end{array}$ & $\begin{array}{r}50276 \\
194155\end{array}$ & $\begin{array}{r}678364 \\
1290640\end{array}$ & All neuroses & - & $\begin{array}{l}\mathbf{M} \\
\mathrm{F}\end{array}$ & $\begin{array}{l}156208 \\
528163\end{array}$ & $\begin{array}{l}1554992 \\
4649497\end{array}$ \\
\hline Depressive disorder & 300.4 & $\begin{array}{l}\mathrm{M} \\
\mathrm{F}\end{array}$ & $\begin{array}{r}74520 \\
249429\end{array}$ & $\begin{array}{r}670680 \\
1840706\end{array}$ & Hypertension & - & $\begin{array}{c}\mathrm{M} \\
\mathrm{F}\end{array}$ & $\begin{array}{l}132123 \\
331543\end{array}$ & $\begin{array}{l}3438765 \\
4691837\end{array}$ \\
\hline All other neuroses & - & $\begin{array}{l}\mathbf{M} \\
\mathbf{F}\end{array}$ & $\begin{array}{l}31412 \\
84579\end{array}$ & $\begin{array}{l}205948 \\
418881\end{array}$ & All diseases & - & $\begin{array}{c}\mathrm{M} \\
\mathrm{F}\end{array}$ & $\begin{array}{r}8349535 \\
15429560\end{array}$ & $\begin{array}{r}66871505 \\
106063040\end{array}$ \\
\hline
\end{tabular}

Table 5a. Direct costs of neurotic disorder in UK general practice 1985 (in pounds sterling)

\begin{tabular}{|c|c|}
\hline & $£$ \\
\hline \multicolumn{2}{|l|}{ Consultation costs } \\
\hline $\begin{array}{l}\text { Total cost of all surgery consultations for } \\
\text { neurosis }\end{array}$ & 64899900 \\
\hline Total cost of all home visits for neurosis & 7671980 \\
\hline Total number of referrals 122243 & \\
\hline Total cost of referrals & 244487 \\
\hline Total cost & 7501676 \\
\hline \multicolumn{2}{|l|}{ Psychotropic drug costs } \\
\hline \multicolumn{2}{|l|}{$\begin{array}{l}\text { Total number of prescriptions for anxiolytics } \\
\text { and antidepressants } 18691000\end{array}$} \\
\hline Net ingredient cost (net of physical diagnoses) & 30957000 \\
\hline Total cost ${ }^{*}$ & $3756167 \theta$ \\
\hline \multicolumn{2}{|l|}{ Personal costs } \\
\hline \multirow{2}{*}{\multicolumn{2}{|c|}{$\begin{array}{l}\text { Total of prescription charges paid by patients } \\
\text { for anxiolytics and antidepressants pre- } \\
\text { scribed for neuroses; } 1985\end{array}$}} \\
\hline & \\
\hline Total direct $\cos t=$ & 119697000 \\
\hline
\end{tabular}

Table $5 \mathrm{~b}$. Direct costs of hypertension in $U K$ general practice 1985 (in pounds sterling)

\begin{tabular}{lr}
\hline & \multicolumn{1}{c}{$£$} \\
\hline Consultation costs & \\
Surgery consultations for hypertension & 36425100 \\
Cost of home visits for hypertension & 5197700 \\
Costs of referrals & 945400 \\
$\quad$ Total GP costs & 42600000 \\
Drug costs & \\
Drugs acting on the heart & 76953800 \\
Diuretics & 35313600 \\
Anti-hypertensives & 40990900 \\
Net ingredient cost & 153258300 \\
$\quad$ Total cost* & 185956000 \\
Personal costs & \\
Prescription charges paid by patients for anti- \\
hypertensives prescribed in 1985 \\
Total cost & 11529300 \\
& Total direct cost \\
\hline
\end{tabular}


Table 6a. Indirect costs of neurotic disorder in UK general practice 1985

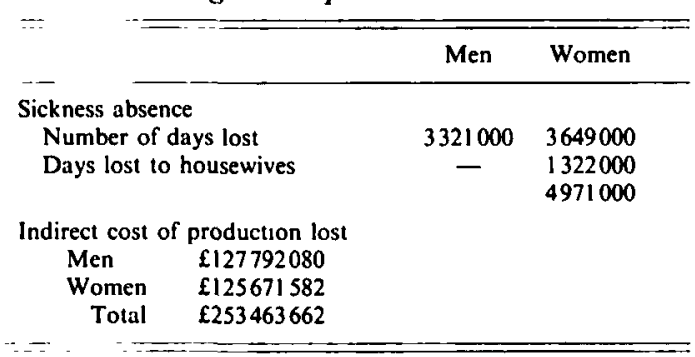

Table $6 \mathrm{~b}$. Indirect costs of hypertension in UK general practice 1985

\begin{tabular}{lcc}
\hline & Men & Women \\
\hline Sickness absence & & \\
Number of days lost & 2028000 & 603500 \\
Days lost to housewives & - & 129700 \\
433200 \\
Indirect cost of production lost & & \\
Men $\quad \begin{array}{l} \\
\text { Women } \quad £ 18535300\end{array}$ & \\
Total $\quad £ 96572700$ & \\
\hline
\end{tabular}

In terms of GP time and lost production, neurotic disorder is the more expensive illness; whereas, uncomplicated hypertension has higher drug costs.

\section{DISCUSSION}

The future of mental health and mental retardation lies in the area of economics, taxation and finance. Neurosis represents a considerable burden upon public resources, the bulk falling in the form of reduced production. In every area, the estimate given here is a minimal one; the true figures are probably much larger.

\section{Consultation costs}

It is likely that the annual consultation rate (240 per 1000 at risk) used in this study is an underestimate of the number of consultations directly attributable to neurotic disorder. There are a number of reasons for this. First, the rate is a measure of the number of consultations where a diagnosis of neurotic disorder was made by the GP. Several studies have highlighted the wide discrepancies between GPs in their recognition of mental disorder (Shepherd et al. 1966; Goldberg \& Kessel, 1975; Marks et al. 1979; Whitehouse, 1987). Shepherd (1983) found that the raw data in the general practice morbidity survey - the source for the figures presented here - revealed that individual practitioners varied substantially in their reported rates of mental illness, diagnosing between $4 \%$ and $65 \%$ of the practice population. Goldberg \& Huxley (1980) estimated that approximately $40 \%$ of patients with psychiatric morbidity seen by GPs did not receive a psychiatric diagnosis.

Also, there is a close relationship between psychiatric and physical illness and the extent to which those who suffer from one also tend to suffer from the other. Shepherd et al. (1966) found that the average number of physical illnesses recorded among psychiatric patients in general practice was $50 \%$ higher than that for non-psychiatric patients. Although some of these may be instances of hidden psychiatric morbidity, there is evidence that psychiatric illness is genuinely associated with a raised level of physical morbidity (Eastwood \& Trevelyan, 1972; Hankin et al. 1983; Wilkinson et al. 1988).

At the same time it has to be recognized that the number of consultations which took place is not necessarily a measure of the opportunity cost in terms of GP consultations. To assume that it is, is to imply that consultations for neurosis use resources which would otherwise be used for other consultations, rather than as a reduction in GPs' workloads. It implies that the supply of consultations is rationed, and that there is a queue of patients waiting for any released GP time.

\section{Personal costs}

As well as paying for prescribed drugs, some people with neurosis spend money on alternative treatments outside the National Health Service, such as clairvoyance, counselling, herbal remedies, homeopathy or acupuncture. The cost and extent of these forms of treatment is largely unexplored. 
Murray \& Shepherd (1988) estimate that approximately $£ 250$ million were spent on non-orthodox medicine in 1985. It seems reasonable to assume that a significant proportion of this money is spent on illnesses which are largely neurotic in origin, but the lack of distinction between mental and physical symptoms which characterizes alternative medicine, makes the exact figure difficult to assess.

Patients with neurotic disorders bear other costs which have no obvious monetary value. 'Soft' costs include symptoms experienced both by the patient and by the care-givers in his or her immediate family, and impairments in the social functioning of the families of those with neurotic disorders. These are very important effects of the illness, but are difficult to quantify. This is one of the major failings of economic analysis of the burden of illnesses. To compare the effects of different services, Glass \& Goldberg (1977) proposed using instruments such as the General Health Questionnaire and the MRC social performance schedule. However, it would be difficult to extend this method to comparisons between illnesses in the absence of a comprehensive general index of suffering.

\section{Lost production}

The figure used in this study is a minimal estimate of the amount of lost production due to neurotic disorder. It measures only days of certificated absence for which mental disorder was the recorded reason. Jenkins' (1985) study of employed men and women found that minor psychiatric morbidity was a major determinant of the level of all types of sickness absence, both certificated and uncertificated. She found that over $32 \%$ of employees with sickness absence were psychiatric 'cases', and that these people missed an average of 8.5 days per year. Comparing this rate with the absence rate for non-cases, of 2.65 days, implies a rate of sickness absence directly attributable to minor psychiatric morbidity of 5.8 days. This implies that the actual number of days of lost production is nearer to 93 million, and the value of production lost around $£ 2.9$ billion, rather than the minimal estimate of $£ 250$ million. This would increase still further if we could quantify the reduced productivity of those with neurotic disorder who continue working, and of those working beside them.

People who suffer from chronic illness tend to drop out of the labour force altogether, and the whole of the production which they could have been expected to produce is lost. Mann et al. (1981) found that $25 \%$ of diagnosed neurotic patients in a general practice sample were classifiable as chronic a year after the initial diagnosis. Chronic disorder was most common in older patients. Thus, according to Morbidity Statistics from General Practice (MSGP, 1986), approximately two million people became neurotic during 1985, of whom 500000 would be chronically ill. If $10 \%$ are so seriously ill that they leave the workforce, at an average age of 50 years, a further 500000 person years (10 years per person) of production will be lost. Assuming an average annual wage of $£ 8247$, and discounting future income at an annual rate of $10 \%$, the value in 1985 of the loss in these expected income-streams would be around $£ 2.7$ billion. Clearly, losses from this source would, if they could be quantified, be significant contributors to the total.

This reinforces our conclusion that the greatest effects of neurotic disorder, and consequently the greatest opportunities for therapeutic progress, lie in the area of lost production and impaired economic functioning of sufferers, rather than stemming from expensive treatment. These latter estimates, which probably lie closer to the truth than the minimal estimates used in the remainder of the paper, imply a cost of 5.6 billion in lost production due to neurosis. If this cost could be eliminated, this would be a saving of over a third of the total cost of the National Health Service.

\section{CONCLUSIONS}

Government estimated costs of minor psychiatric morbidity in the secondary care setting are enormous: at 1985 prices, over $£ 189$ million and $£ 30$ million for hospital in-patient and outpatient expenditure, respectively. On top of this, our minimal estimate of the costs of neurotic 
disorder in UK general practice for 1985 is $£ 373$ million. The methodology employed in obtaining this figure, and that for uncomplicated hypertension, is described. The costs of these illnesses were estimated to be similar; however, disaggregating their costs showed important differences.

The greatest effects of neurotic disorder and, consequently, the greatest opportunities for therapeutic progress lie in the area of lost production and impaired economic functioning of sufferers, rather than stemming from expensive treatment.

\section{CROFT-JEFFREYS AND G. WILKINSON}

This work was undertaken at the General Practice Research Unit and supported by the Department of Health. We are very grateful for direction from Professor Michael Shepherd. We are also indebted to Dr Rachel Jenkins (Principal Medical Officer), Robert Anderson (Economic Adviser's Office) and Phillip Alexander (Statistics and Research Division), all from the Department of Health, for their helpful advice and for providing information incorporated in the text.

\section{APPENDIX A}

\section{List of psychotropic drugs commonly prescribed for neurotic disorder}

Antidepressant drugs

Amitriptyline

Butriptyline

Clomipramine hydrochloride

Desipramine hydrochloride

Dothiepin hydrochloride

Doxepin

Imipramine hydrochloride

Iprindole

Iproniazid

Isocarboxazid

Lofepramine

Maprotiline hydrochloride

Mianserin hydrochloride

Nortriptyline

Phenelzine

Protriptyline hydrochloride

Tranylcypromine

Trazodone hydrochloride

Trimipramine

\section{REFERENCES}

Andrews, G., Hall, W., Goldstein, G., Lapsley, H., Bartels, R. \& Silove, D. (1985). The economic costs of schizophrenia. Implications for public policy. Archives of General Psychiatry 42, 537-543.

Balestrieri, M., Williams, P. \& Wilkinson, G. (1988). Specialist mental health treatment in general practice: a meta-analysis. Psychological Medicine 18, 711-717.

Berry, W. D. \& Boland, A. (1977). The Economic Costs of Alcohol Abuse. Free Press: New York.

Birnbaum, A. (1978). The Costs of Catastrophic Illness. Lexington Books: Lexington.

Black, D. \& Pole, J. (1975). Priorities in biomedical research; indices of burden. British Journal of Preventive and Social Medicine 29, 222-227.

Central Statistical Office (1987). Social Trends 17, HMSO: London.

Cooper, E. M. \& Rice, D. (1976). Estimating the costs of illness. Social Security Bulletin 39, 21-36.

Department of Health and Social Security (1978, 1979, 1980, 1981, 1982). Social Security Statistics. DHSS: London.
Tryptophan

Viloxazine hydrochloride

Benzodiazepines
Alprazolam
Bromazepam
Chlordiazepoxide
Clobazam
Clorazepate dipotassium
Diazepam
Ketazolam
Lorazepam
Medazepam
Oxazepam
Prazepam
Other anxiolytics
Chlormezanone
Hydroxyxine hydrochloride
Meprobromate

Department of Health and Social Security (1987). Social Security Statistics. DHSS: London.

Eastwood, M. R. \& Trevelyan, M. H. (1972). Relationship between physical and psychiatric disorder. Psychological Medicine 2, 363-372.

Fenton, F. R., Tessier, L., Contandrioupoulos, A. P., Nguyen, H. \& Struening, E. L. (1982). A comparative trial of home and hospital psychiatric treatment: financial costs. Canadian Journal of Psychiatry 27, 177-187.

Fischer-Homberger, E. (1983). Neurosis. In Handbook of Psychiatry Volume 1. General Psychopathology (ed. M. Shepherd and O. L. Zangwill), pp. 40-42. Cambridge University Press: Cambridge.

Fry, J. (1980). On the nature and natural history of common diseases. In Primary Care (ed. J. Fry), pp. 305-312. Heinemann: London.

Ginsberg, G. \& Marks, I. (1977). Costs and benefits of behavioural psychotherapy: a pilot study of neurotics treated by nursetherapists. Psychological Medicine 7, 685-700.

Ginsberg, G., Marks, I. \& Waters, H. (1984). Cost-benefit analysis of a controlled trial of nurse therapy for neuroses in primary care. Psychological Medicine 14, 683-690. 
Glass, N. J. \& Goldberg, D. (1977). Cost benefit analysis and the evaluation of psychiatric services. Psychological Medicme 7 . 701-707.

Goldberg, D. \& Huxley, P. (1980). Mental Illness in the Community; the Pathway to Psychtatric Care. Tavistock Publications: London.

Goldberg, D \& Kessel, N. (1975). Research in general practice. In Methods of Psychtatric Research (ed. P. Sainsbury \& N Kreitman), pp. 242-263. Oxford University Press: Oxford.

Gunderson, J. \& Mosher, L. (1975). The cost of schizophrenia. American Journal of Psychiatry 132, 901-906.

Hankin, J. R., Kessler, L. G., Goldberg, I. D., Steinwachs, D. M. \& Starfield, B. H. (1983). A longitudinal study of offset in the use of non-psychiatric services following specialized mental health care American Journal of Public Health 21, 1099-1110.

Hartunian, F. (1980). Incidence and Economic Costs of Major Health Impairments. Lexington Books: Lexington.

Herzman, P. (1983). The economic costs of mental illness in Sweden 1975. Acta Psychiatrica Scandinavica 68, 359-367.

Jenkins, R. (1985) Minor psychiatric morbidity in employed young men and women and its contribution to sickness absence. British Journal of Industrial Medicine 42, 147-154.

McKechnie, A. A., Rae, D. \& May, J. (1982). A companson of inpatient costs of treatment and care in a Scottush Psychiatric hospital. Britush Journal of Psychiatry 141, 602-607.

Mangen, S. P., Paykel, E. S., Griffith, J. H., Burchell, A. \& Mancinı, P. (1983). Cost-effectiveness of community psychiatric nurse or out-patient psychiatrist care of neurotic patients. Psychological Medicine 13, 407-416.

Mann, A. H. (1984). Hypertension: Psychological Aspects and Diagnostic Impact in a Clinical Trial. Psychological Medicine Monograph Supplement 5 Cambridge University Press: Cambridge.

Mann, A. H., Jenkins, R. \& Bessey, E. (1985). The twelve month outcome of patients with neurotic illness in general practice. Psychological Medicine 11, 535-550.

Marks, J., Goldberg, D. P. \& Hillier, V. F. (1979) Determinants of the ability of general practitioners to detect psychiatric illness. Psychological Medicine 9, 337-353.

Murray, J. \& Shepherd, S. (1988). Alternative or additional medicine? A new dilemma for the doctor. Journal of the Royal College of General Practitioners 38, 511-514.

National Audit Office (1989), National Health Service Coronary Heart Disease. HMSO: London.
Office of Health Economics (1987). Compendium of Health Statistics. Sixth Edition, 1987. HMSO: London.

Royal College of General Practitioners, Office of Population, Census and Surveys \& Department of Health and Social Security (1979). Studies on Medical and Population Subjects No. 36. Morbidity Statistics from General Practice, Second National Study, 1971-2. RCGP, OPCS, DHSS: London.

Royal College of General Practitioners, Office of Population, Census and Surveys \& Department of Health and Social Security (1986). Studies on Medical and Population Subjects No. 36. Morbidity Statistics from General Practice, Third National Study, 1981-2. RCGP, OPCS, DHSS: London.

Shepherd, M., Cooper, B., Brown, A. C. \& Kalton, G. (1966) Psychiatric Illness in General Practice. Oxford University Press: Oxford.

Shepherd, M. (1983). Mental disorder and primary care in the United Kingdom. Journal of Public Health Policy 4, 8388.

Sims, A. C. P. (1978). Hypotheses linking neuroses with premature mortality. Psychological Medicine 8, 255-263.

Sims, A. C. P. \& Prior, M. P. (1978). The pattern of mortality in severe neuroses. British Journal of Psychiatry 133, 299-305.

Weisbrod, B. A. (1981). Benefit-cost analysis of a controlled experiment : treating the mentally ill. Journal of Human Resources $16,523-548$.

Weisbrod, B. A., Test, M. \& Stein, L. (1980). Alternative to mental hospital treatment (ii economic benefit-cost analysis). Archives of General Psychiatry 37, 400-405.

Westcott, R. (1977). The length of consultations in general practice. Journal of the Royal College of General Practitioners 27, 552-555.

Whitehouse, C. (1987). A survey of the management of psychological illness in general practice in Manchester. Journal of the Royal College of General Practitioners 37, 112-115.

Wilkinson, G., Smeeton, N., Skuse, D. \& Fry, J. (1988). Consultations for physical illnesses by patients diagnosed and treated for psychiatric disorders by a general practitioner: 20 year follow-up study. British Medical Journal 297, 776-778.

Williams, P. (1978). Physical ill-health and psychotropic drug prescription - a review. Psychological Medicine 8, 683-693.

WHO (1978). Mental Disorders: Glossary and Guide to their Classification in Accordance with the Ninth Revision of the International Classification of Diseases. World Health Organization: Geneva. 